\title{
MENJAWAB MIMPI KESEJAHTERAAN NELAYAN TRADISIONAL DI KELURAHAN MALALAYANG I KOTA MANADO PROPINSI SULAWESI UTARA
}

\author{
Max Wagiu \\ Program Studi Agrobisnis Perikanan, \\ Fakultas Perikanan dan IImu Kelautan. UNSRAT. Manado 95115.
}

ABSTRACT

Economic and social prosperity is a dream of all traditional fishermen particularly those who live in Malalayang I, Manado, North Celebes. This study used interviews to gather the information. Results found that 1) the local fishermen need to move to a semi-industrial fishing gear and boat in order to increase their catches;-2) the fishermen need to have an investment support to provide better fishing gears. Improvement in their economic and social conditions would bring improvements in social relationship among local fishermen.

\section{Keyword : Fisherman Community Dream, Malalayang, Manado}

\section{PENDAHULUAN}

Usaha perikanan pancing ulur adalah suatu bentuk usaha masyarakat nelaya tradisional dengan menggunakan peralatan yang serba sederhana. Usaha ini, biasa dilakukan oleh keluarga nelayan secara turun temurun tanpa perubahan dan perkembangan.

Dari aspek sosial, pandangan masyarakat nelayan tradisional tentang dirinya ${ }^{\circ}$ dan masyarakatnya, membentuk mereka menjadi sangat ekslusif denganyorientasi internal yang mendasari pandangan-pandangan sosial dan hubungannya dengan masyarakat lingkungan yanglebih luas.

Mereka membentuk suatu ikatan priordinal yang kuat membentuk keyakinan dalam diri mereka kalau inilah jalan hidup mereka, sehingga sulit menerima sesuatu yang baru yang didasarkan pada perkembangan ilmu dan teknologi di bidang usaha perikanan. Pandangan hidup mereka yang ekslusif inj membawa mereka pada cara pandang dan perilaku hidup yang membentuk suatu garis batas yang tegas antara kelomplok mereka dengan kelompok yang lain.

Prinsip hidup seperti ini membawa kondisi sosial yang semu, antara kami dan kamu, sehingga kata kita seakan menghilang dari ingatan. Pandangan masyarakat lingkungan yang dipicu oleh opini ekslusifitas, mendorong masyarakat lingkungan se- kitar berpandangan négatif terhadap kelompok masyarakat nelayan tradisional.

Kedua pandangan yang berpangkal pada kecurigaán masing-masing pada kelompok satu dan lainnya, secara kumulatif akan saling memperkuat bergerak ke arah yandg bertentangan dan pada akhirnya menciptakan jurang sosial yang lebar antara masyarakat nelayan tradisional dan masyarakat di lingkungannya. Kondisi ini dikenal dengan hipotesa mydral yang disekitarnya caudasi sirkuler-kumulatif (Hersey and Blanchord, 1974).

Untuk mengubah kondisi negatif ini, jalan satu-satunya ialah mengangkat taraf hidup nelayan tradisional secara ekonomi, sosial serta budaya. Meningkatnya taraf hidup ekonomi dan sosial masyarakat nelayan tradisional akan memberi mereka suatu status sosial yang setara dengan kelompok masyarakat lain sehingga tekanan-tekanan sosial yang berdampak negatif bagi mereka akan berkurang seiring dengan kemajuan yang dicapai.

Penelitian kehidupan sosial ekonomi masyarakat nelayan tradisional di Kelurahan Malalayang I Kota Manado dimaksudkan untuk meningkatkan taraf hidup ekonomi dan sosial mereka melalui upaya peningkatan produksi hasil tangkapan ikan.

Diduga, penggunaan alat tangkap tradisional yang disebut pancing ulur, baik kuantitas maupun kualitas, maka sebagai langkah pertama, diteliti sejauh mana peng- 
gunaan peralatan tangkap semi modern mempengaruhi produksi hasil tangkapan.

Dari hasil penelitian ini, akan dirancang suatu model investasi dan pemberian modal kerja terbatas yang diperlukan untuk upaya pengembangan usaha perikanan pancing ulur tersebut yang diharapkan akan meningkatkan taraf hidup ekonomi dan sosial.

Selanjutnya, ekonomi dan sosial yang meningkat memicu perubahan pandangan masyarakat sekitar dari negatif berangsur menjadi semi positif dan selanjutnya menjadi positif. Sikap status quo yang tadinya mendominasi persepsi sosial di kedua kelompok masyarakat ini akan mencair seiring dengan berkembangnya taraf hidup masyarakat nelayan tradisional.

\section{METODOLOGI PENELITIAN}

Sebanyak 21 orang nelayan dari 41 nelayan yang ada di kelurahan Malalayang I, Kota Manado telah diambil contoh ( $n=21$ atau $>50 \%$ ). Data diperoleh melalui wawancara dengan menggunakan petunjuk wawancara. Penelitian ini juga mengumpulkan data sekunder yang diperoleh dari berbagai publikasi guna memperkaya bahasan.

Analisa data dilakukan dêngan mengaplikasikan statistika infereñsiał dengan bantuan perangkat lunak SPSS 13.0, selanjutnya dilakukan analisa keuangan untuk mengukur tingkat kelayakan investasi, yang meliputi analisa cash flow, IRR, BEP, profit ability idex, Asset Turn Over dan Return On Investment (ROI) dan Break Even Quantity (BEQ).

\section{HASIL PEMBAHASAN}

Hubungan antara variabel tidak bebas dengan variabel bebas alat produksi mengggnakan teknik analisis pearson pada taraf kepercayaan 95\% menunjukkan hubungan antar variabel yang sangat berarti $(r=0,96)$ dengan koefisien determinasi $\left(r^{2}=0,895\right)$.

Hal ini menunjukkan bahwa tingkat produksi tangkapan ditentukan oleh peralatan dan perlengkapan tangkap sebesar $89,5 \%$ dan oleh faktor lainnya $10,5 \%$. Analisis keragaman menunjukkan adanya hu- bungan regresif yang sangat sangat berarti antara alat tangkap dan hasil produksi tangkap.

Peningkatan produksi hasil tangkapan sangat ditentukan oleh kualitas dan kuantitas alat tangkap dan ini memerlukan investasi terbatas pada peralatan dan ketersediaan modal kerja kepada nelayan tradisional di kelurahan Malalayang I Kota Manado. Pemberian investasi terbatas ini dimaksudkan agar nelayan tidak menjalani cultural shock (Bour, 1965) dan dimulai dengan penyediaan alat tangkap semimodern dilengkapi dengan penggunaan motor tempel untuk memperlyas daerah jangkauan penangkapan.

Tabel 1. Rencana Investasi Modal Kerja.

\begin{tabular}{|c|c|c|}
\hline \multicolumn{3}{|c|}{ A. INVESTASI } \\
\hline 1 & 1 Unit perahu & 4.000 .000 \\
\hline 2 & 1 Unit motor tempel 5,5 PK & 6.000 .000 \\
\hline 3 & 3 Buah lampu petromax @ Rp 350.000 & 1.350 .000 \\
\hline 4 & 3 Unit pancing @ Rp 1.000.000 & 3.000 .000 \\
\hline 5 & Lain-lain & 800.000 \\
\hline \multicolumn{2}{|r|}{ TOTAL (A) } & 15.150 .000 \\
\hline \multicolumn{3}{|c|}{ B. MODAL KERJA } \\
\hline 1 & Upah pemancing: $3 \times 1 \times$ Rp 2.000 .000 & 6.000 .000 \\
\hline & Perawatan perahu dan motor & 500.000 \\
\hline 3 & Perawatan pancing $3 \times \mathrm{Rp} 100.000$ & 300.000 \\
\hline 4 & Perawatan petromax $3 \times \operatorname{Rp} 50.000$ & 15.000 \\
\hline 5 & Solar : 15 trip $\times 10 \operatorname{Itr} \times \operatorname{Rp} 4.500$ & 675.000 \\
\hline 6 & Minyak tanah $3 \times 10 \times 2 \times 6 \times \operatorname{Rp} 3.000$ & 720.000 \\
\hline 7 & Bahan makanan $15 \times 3 \times 2 \times 15.000$ & 1.350 .000 \\
\hline \multicolumn{2}{|r|}{ TOTAL (B) } & 9.560 .000 \\
\hline \multicolumn{2}{|r|}{ TOTAL $(A+B)$} & 24.710 .000 \\
\hline
\end{tabular}

Tabel 2. Penyusutan Asset,

\begin{tabular}{llcccr}
\hline No & Jenis asset & Jumlah & $\begin{array}{c}\text { Umur } \\
\text { teknis } \\
\text { (tahun) }\end{array}$ & $\begin{array}{c}\text { Nilai buku } \\
\text { (Rp) }\end{array}$ & $\begin{array}{c}\text { Penyusutan } \\
\text { per tahun }\end{array}$ \\
\hline 1 & Perahu & 1 & 3 & $3,000,000$ & $1,000,000$ \\
2 & Motor 5 pk & 1 & 5 & $6,000,000$ & $1,200,000$ \\
3 & Petromax & 3 & 3 & $1,050,000$ & 350,000 \\
4 & Alat pancing & 3 & 2 & $3,000,000$ & $1,500,000$ \\
& & & Rp $13,050,000$ & Rp $4,050,000$ \\
\hline
\end{tabular}

Berdasarkan data tahun 2004-2008, hasil perhitungan produksi menunjukkan adanya peningkatan produksi tangkapan sebesar 30 ton/tahun sejalan dengan penambahan dan perbaikan kualitas alat pancing (semi-modern), dimana produksi menjadi 240 ton pada tahun 2008 yang dihasilkan oleh 21 nelayan contoh dengan ratarata menggunakan tiga alat pancing ulur. Produksi rata-rata nelayan contoh tahun 2008 adalah sebesar $11.428,5 \mathrm{~kg}$ atau 952 $\mathrm{kg} / \mathrm{bulan}$. Dengan menggunakan produksi rata-rata/tahun tersebut sebagai patokan perhitungan, maka produksi tahunan dalam 


\section{Menjawab Mimpi Kesejahteraan Nelayan}

5 tahun berikutnya menggunakan rumus $\mathrm{Pt}=\mathrm{Po}(1+5)^{2}$ dimana $\mathrm{Pt}$ adalah produksi tahun ke $t$ dan Po adalah produksi pada tahun awal perhitungan dan $r$ adalah peningkatan produksi tiap tahun (25\%).

Berawal dari pertumbuhan produksi tangkapan 2004-2008 dengan peningkatan rata-rata $25 \%$ per tahun (Majid, 2009), maka dalam tahun penelitian ini, pertumbuhan produksi hasil tangkapan hanya diprediksi $10 \% /$ tahun agar tidak over estimate meskipun penambahan dan perbaikan kualitas alat tangkap ternyata berkorelasi secara positif $\left(r=0,96\right.$ dan $\left.r^{2}=0,856\right)$.

Dengan penggunaan motor tempel 5,5 pk, jangkauan daerah tangkapan ikan akan bertambah luas dan dengan diikuti oleh perbaikan manajemen usaha baik dari segi fungsi manajemen maupun unsur dan sistem manajemen maka pertumbuhan produksi $10 \%$ rata-rata per tahun cukup realistis (Tabel 3 ).

Tabel 3. Pertumbuhan produksi tangkapan 20102013.

\begin{tabular}{lccccr}
\hline Tahun & $\begin{array}{c}\text { Produksi } \\
\mathbf{2 1} \text { nelayan } \\
\text { sampel } \\
\mathbf{( k g )}\end{array}$ & $\begin{array}{c}\text { Produksi } \\
\text { rata-rata } \\
\text { per } \\
\text { nelayan } \\
\mathbf{( k g )}\end{array}$ & $\begin{array}{c}\text { Harga } \\
\text { jual } \\
\text { rata- } \\
\text { rata }\end{array}$ & $\begin{array}{c}\text { Hasil } \\
\text { penjualan } \\
\text { (Rp) }\end{array}$ & $\begin{array}{c}\text { Pertum- } \\
\text { buhan }\end{array}$ \\
\hline $2004-$ & 120,000 & 5,714 & 9,362 & $53,497,142$ & 25 \\
2008 & & & & & \\
2010 & 264,000 & 12,571 & 9,362 & $117,689,702$ & 10 \\
2011 & 29,040 & 13,328 & 9,362 & $129,457,736$ & \\
2012 & 319,142 & 15,211 & 9,362 & $142,405,362$ & \\
2013 & 361,384 & 16,732 & 9,362 & $156,644,984$ & \\
\hline Sumber : Majid 2009 & & & & &
\end{tabular}

Tabel 4. IRR (Internal Rate of Return) dan PI (Profit ability Indeks).

\begin{tabular}{rrrrrr}
\hline \multirow{2}{*}{ Tahun } & \multirow{2}{*}{ NCF } & \multicolumn{2}{c}{ DF $=\mathbf{1 2} \%$} & \multicolumn{2}{c}{ DF $=\mathbf{4 0 \%}$} \\
\cline { 3 - 6 } & & df & \multicolumn{1}{c}{ NPV } & df & \multicolumn{1}{c}{ NPV } \\
\hline 2009 & $(25,000,000)$ & 1.00 & $(25,000,000)$ & 1.00 & $(25,000,000)$ \\
2010 & $55,051,652$ & 0.89 & $49,106,073$ & 0.71 & $39,306,879$ \\
2011 & $96,953,916$ & 0.74 & $72,137,713$ & 0.51 & $49,446,497$ \\
2012 & $138,091,348$ & 0.62 & $85,616,635$ & 0.36 & $50,265,250$ \\
2013 & $179,624,120$ & 0.52 & $92,686,045$ & 0.26 & $46,702,271$ \\
\hline \multicolumn{3}{c}{ Jumlah } & $274,546,456$ & & $160,720,697$ \\
\hline
\end{tabular}

Dengan menggunakan rumus $I R R=$ $i_{1}+\left[N P V{ }^{1}\left({ }_{2}-i_{1}\right)\right] / N P V$ pos-NPV neg, diperoleh IRR $=79,5 \%$, karena bunga bank saat ini adalah $15 \%$ per tahun, maka investasi sebesar $\operatorname{Rp} 25.000 .000 /$ nelayan pancing ulur di kelurahan Malalayang I kota Manado layak secara finansial. Dengan investasi sebesar itu, menghasilkan indeks keuntungan (profit ability $=\mathrm{PI}$ ) sebesar Rp 104.979.714 (dari 0,892 x Rp 117.689.702) atau PI sebesar 4,19, berarti investasi tersebut layak secara finansial $(4,19>1)$

\section{BEP (Break Even Point)}

Selanjutnya dengan biaya tetap $R p$ 337.500 harga jual $R p$ 9.362/unit dan biaya variabel $R p$ 4.155/unit, diperoleh (BEP= Total biaya tetap/harga jual per unit-biaya variabel per unit) diperoleh $B E P=\operatorname{Rp~64,81.~}$ Jadi pada harga $\mathrm{Rp} 64,81 / \mathrm{Kg}$ usaha ini mencapai titik impas. Asset Turn Over (ATO)=Total penjualan/Asset adalah 8,3 kali. Analisa BOQ (Break Even Quantity) dimaksudkan untuk mengetahui bêrapa besar jumlah unit yang terjuar untuk mendapatkan titik pulang pokøk (impas), yaitu:

$B E Q=F / p-c=R p 337.500 / 9.362<4.155,4=64,8 \mathrm{Kg}$

Harga pokok penjualan

$(\mathrm{HPP})=(\mathrm{FG}+\mathrm{VC}) / \mathrm{TP}$

(337.500-54.900.000)/42.571=Rp 4.394,04

Perhitungan-ini tidak dapat dijadikan dasar bagi penentuan HPP karena harga rata-rata ikan di tingkat konsumen sebesar Rp $20.000 / \mathrm{Kg}$. Ini menunjukkan bahwa keuntungan para pedagang terlalu besar karena rata-rata yang dibayarkan kepada tnelayan hanya Rp 9.362/Kg (Majid, 2009), dan oleh karena itu, pemerintah kota perlu campur tangan dalam menetapkan harga beli ikan di tingkat nelayan, misalnya dengan menetapkan HET (Harga Eceran Tertinggi) di tingkat konsumen sebesar $\mathrm{Rp}$ $15.000 / \mathrm{Kg}$ dan jika pedagang boleh mengambil keuntungan 25\% maka HPP menjadi 100/125xRp 15.000=Rp 12.000. Inilah HPP yang dianggap wajar dalam penelitian ini untuk dibayarkan kepada nelayan sehingga setiap nelayan akan mendapat tambahan penghasilan pada tahun 2010 sebesar Rp 33.162.990. Jumlah ini akan sangat berarti bagi usaha meningkatkan kesejahteraan ekonomi masyarakat nelayan tradisional dan memperbaiki status sosial mereka.

\section{Laba rugi}

Perhitungan laba rugi dihitung sebagai berikut:

Penerimaan hasil penjualan $\mathrm{Rp}$. 117.689.702 sementara total pengeluaran Rp. 61.750.000 yang terdiri dari penyusutan aset $R p$ 3.850.000, biaya bunga $R p$. 3.000.000, upah Rp. 30.000.000 dan liabilitas Rp. 24.900.000. dengan demikian pendapatan sebelum pajak adalah Rp. 55.939.702, jika pajak penghasilan dikena- 
kan 25\% yakni sebesar Rp. 41.954.777. Pendapatan ini akan bertambah lagi dengan adanya intervensi pemerintah dalam penetapan harga beli di tingkat nelayan sebesar Rp. 12.000 dimana nelayan akan memperoleh tambahan penghasilan Rp. 33.162.990 per tahun.

Pemberdayaan masyarakat nelayan akan membawa perubahan dalam status ekonomi dan sosial mereka dan hal ini akan merubah sikap sosial lingkungan dan masyarakat nelayan itu sendiri, yang berkembang ke arah lebih positif, saling memperkuat dan hal ini akan memperkecil jarak sosial antara semua kelompok masyarakat.

Untuk pengembangan masyarakat nelayan tradisional di kelurahan Malalayang I, perlu dilakukan hal-hal sebagai berikut:

- Pengelompokan nelayan dalam wadah koperasi atau yang disebut Small Fisherman's Association dimana mereka secara tetap dapat mendiskusikan setiap masalah dalam usaha mereka dan menemukan pemecahannya.

- Perbaikan dan penambahan alat tangkap melalui investasi terbatas dan terukur guna peningkatan produksi hasil tangkapan. Investasi terbatas dan terukur dimaksudkan agar nelayan tidak mengalami cultural shock apabila langsung diberikan alat tangkap yahg, super modern.

- Perlu diupayakan pelatihan̂ manajemen usaha untuk mendorong helayan berusaha secara efektif dar efisien dalam usaha penangkapan ikan yang berkelanjutan.

- Dengan membaiknya kondisi sosial dan ekonomi masyarakat nelayan tradisional, proses kemiskinan yang bersifat struktural secara bertahan akan berubah dan mencairkan hubungan sosial yang kaku dan stagnan di antara kelompokjmasyarakat.

\section{KESIMPULAN}

Peningkatan produksi tangkapan nelayan sangat dipengaruhi oleh jumlah dan kualitas alat tangkap yang semi modern.
Tingkat kesejahteraan ekonomi dan sosial nelayan tradisional di kelurahan Malalayang I Kota Manado dapat membaik melalui peningkatan produksi dengan memberikan dana investasi terbatas sebesar Rp. 25.000.000. dengan investasi tersebut, dalam finansial analysis yang penulis lakukan.

HPP yang memenuhi rasa keadilan bagi masyarakat nelayan adalah $R p$. $12.000 / \mathrm{Kg}$. Pemerintah perlu mengintervensi harga jual di tingkat nelayan dengan menetapkan harga dasar di tingkat nelayan Rp. $12.000 / \mathrm{Kg}$

Perbaikan status ekonomidan sosial masyarakat nelayan akan berangsur-angsur mengurangi tekanan sosial terhadap masyarakat nelayan dan sejalan dengan itu akan membaur perubahan dalam sikap dan perilaku sosial di antara kelompokkelompok masyarakát. Perubahan penulis yakini akan secara bertahap mengurangi tingkat kemiskinan masyarakat nelayan.

\section{DAFTAR PUSTAKA}

Chaffee FE, 1985, The Models of Strategy, Academic of Management Review

Danodara A, 1992, Corporate Finance, Theory and Practise, John Willy \& Son

Graven HW, 1980, Marketing decision making. Concept and strategy

Ferris K, 1992, How to understand financial statement

Majid D.S, 2009, Kajian sosial ekonomi nelayan pemilik usaha pancing ulur di Kelurahan Malalayang I Kota Manado, PPIK, UNSRAT

Rangkuti F, 2000, Bsiness Plan, Gramedia Pustaka Utama

Rangkuti F, 2001, Analisis SWOT, Gramedia Pustaka Utama

Revsine L, 1998, Financial reporting and analysis, New Jersey 